\title{
BOOK AND MEDIA REVIEWS
}

\section{In the Hands of Doctors: Touch and Trust in Medical Care}

Paul E. Stepansky

Santa Barbara, California, Praeger, 2016, 317 pp., \$48, hardcover

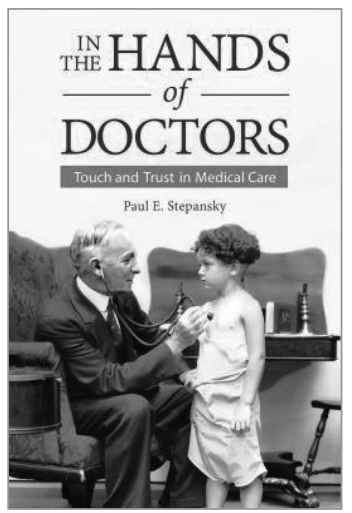

I chose to review this book because of its subtitle. Touch and trust, I believe, are essential elements of my work as a family physician, as they are in the work of many of my family medicine colleagues. I looked forward to reading about the historical importance of these two factors on the physician-patient relationship, especially as it was influenced by the introduction of new medical technologies and the use of procedures in primary care practice.

Unfortunately, however, this book was a huge disappointment. Billed as a "comparative historical approach" to topics concerning the nature and goals of medical education and practice, it comes across as more of a hodgepodge of family-of-origin anecdotes and personal judgments than rigorous scholarship. A few chapters do review how then-novel diagnostic equipment changed the complexion of medicine in the 19th and early 20 th centuries, and there is a chapter on the introduction of nurse practitioners and physicians' assistants after 1960. These are interesting, informative, and well referenced.

The rest is an odd mixture: part paean to the author's general practitioner father (referencing a previously published work $)^{1}$; part random reflections on encounters with his retinologist and dentist; and part protracted argument in favor of abandoning family medicine in favor of a new specialty, "procedural care medicine", based for the most part on the tenets of profit, prestige, and procedures.

Throughout the book, the author fails to see our work as more than a compilation of subspecialty-based approaches to patient problems. He condescendingly eschews current models for training students and residents in patient and relationship-centered care. And, according to him, our discipline is at its foundation a

\footnotetext{
... semantically strained, even oxymoronic, vision of a non-specialty specialty, a specialty that rejected specialist values, was an amalgam of 1960 s counterculture, the social sciences, and a dash of psychoanalytic object relations theory (per Michael Balint), all abetted by the dearth of "personal physicians" and the emergence in the 1970s of the patient rights movement. (p. 174)
}

I do not deny there are many challenges to practicing family medicine, and that many barriers limit the establishment of trust and touch as therapeutic modalities in the current medical milieu. In choosing neither to explore beyond the very surface of the family medicine literature nor observe family physicians at work with patients, however, the author (a "Yale-trained historian of ideas specializing in the history of American medicine and psychiatry") does little to address these concerns. Although other readers may disagree with my assessment-In the Hands of Doctors did win a 2017 Independent Publisher Book Award bronze medal in the Health/Medicine/Nutrition category - this book mostly demonstrates how the study of history can be misused to make claims based primarily on opinion.

For us as family physician educators, the real message of this book is that many people, even highly regarded scholars, are ignorant of what we do and how we practice. We must at every step along our way speak truth to power. We must advocate for quality primary care services for our patients. We must continue to educate the next generation of physicians as to the beneficial effects of person-centered care and family medicine on the health and wellbeing of people and communities. ${ }^{2-5}$

doi: 10.22454/FamMed.2018.814201

\section{William Ventres, MD, MA}

Department of Family and Preventive Medicine University of Arkansas for Medical Sciences Little Rock, AR 


\section{References}

1. Stepansky PE. The Last Family Doctor: Remembering My Father's Medicine. Upper Montclair, NJ: Keynote Books, LLC; 2011.

2. Epstein RM, Fiscella K, Lesser CS, Stange KC. Why the nation needs a policy push on patient-centered health care. Health Aff (Millwood). 2010;29(8):1489-1495.

3. Starfield B, Shi L, Macinko J. Contribution of primary care to health systems and health. Milbank Q. 2005;83(3):457-502.

4. Stange KC, Ferrer RL. The paradox of primary care. Ann Fam Med. 2009;7(4):293-299.

5. Phillips RL Jr, Pugno PA, Saultz JW, et al. Health is primary: family medicine for America's health. Ann Fam Med. 2014;12(suppl 1):S1-S12

\section{Relationship Power in Health Care: Science of Behavior Change, Decision Making, and Clinician Self-Care}

John Livingstone and Joanne Gaffney

Boca Raton, FL, Taylor \& Francis, 2016, 272 pp., \$44.05, paperback

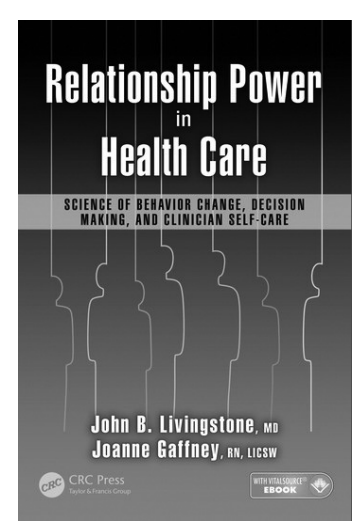

Producing longlasting behavioral and lifestyle changes for patients is a challenging goal for many in health care. As a result, providers may not only use unwarranted variations of treatment for complex problems, but also experience rates of burnout and compassion fatigue from high-utilizing patients. Relationship Power in Health Care helps address these training and competency gaps, providing concrete information on theoretical orientations, decision-making skills and interviewing techniques to address complex patient visits and problems. John Livingstone and Joanne Gaffney, two skilled providers with extensive psychotherapy experience, offer a wealth of knowledge from their clinical and educator roles in medical schools and training programs. Throughout this text, it was impressive to read the authors' mission to improve the science of relationships in medicine, both between providers and patients, and the psychological state of providers themselves.

The book is divided into five distinct parts, with web-based case studies that are effectively woven into different sections. The first part is a nice refresher for providers to acknowledge the importance of interpersonal relationships and patient-centered skills when improving patient encounters. The second part presents certain behavior change models (eg, transtheoretical model, health belief model) and decision-making models (eg, shared medical decision-making, clinical intuition) that can be applied in practice with patients and families. The authors expand on the principles of relationship psychology and the advances in neuroscience with a dense but thorough review of evidenced-based treatment models. Part three introduces how clinicians can integrate past and present models of care, while formulating new hypotheses of decision-making that impact the wellness areas of providers. The fourth part transitions into specific interviewing skills that are important for providers to acquire in routine practice, following up more in-depth on the clinical case vignettes from part one. In the fifth section, specific tips and suggestions are offered for educators of health care trainees, along with information on health coaching and future research in this area. It was a little surprising how briefly this last section was covered, given the authors' backgrounds as advocates for student and resident education.

Overall, the book is well written and educates multiple providers on improving the relationships between both health care teams and patients. Several chapters (specifically chapters 9,10 , and 11 on interviewing skills) could be used as instructional material for residents, behavioral health providers, nurses, and administrators. The online modules are also a novel way to apply the skills and techniques highlighted in the text, illustrating the thoughts that both authors had of each health scenario. These scenarios illustrate effective interviewing skills applied by Gaffney to a number of clinical issues, such as smoking cessation, management of diabetes, and decision-making processes around breast cancer. While the book does not offer as many hands-on skills as other books on health behavior change, motivational interviewing or provider burnout, the authors do provide a thorough theoretical context to traditional psychotherapy and neuroscience practices.

There were only a few disappointments. While the authors cover a variety of clinical topics around theory, health decision-making, and interviewing skills in practice, it almost felt that there were three separate books compressed into one. The book would have been better served by focusing strictly on behavioral interventions and approaches to use with patients in a variety of health care settings. 
Attempting to address clinician burnout and fatigue in practice would have warranted a deeper explanation of this phenomenon, where recent texts highlight health consequences and wellness strategies in full depth. Additionally, most of the theoretical models and interviewing skills did not have a strong family or caregiver focus. Because many medical disciplines do not receive adequate systems training or family interviewing techniques, one of the case vignettes could have included a family case that demonstrates social and relational issues tied into the presenting medical problem.

Relationship Power in Health Care shows strong application of the teamwork and collaboration needed in primary care and other collaborative settings. As a behavioral health provider and educator for residents, I have seen first-hand the importance of developing strong interpersonal relationships with other providers in practice. Livingston and Gaffney offer valuable ways for clinicians to not only deepen their patient-centered skills, but also to emphasize a team-based approach to help patients and families make better-informed decisions around their health. As our health care system is placing increased pressures on medical providers regarding outcomes and performance, this book gives a thorough framework for providers needing tangible skills to improve both patient change and relational wellness in practice.

doi: 10.22454/FamMed.2018.900150

Max Zubatsky, PhD

Department of Family and Community Medicine Saint Louis University

\section{Family Medicine: Principles and Practice, 7th Edition}

Paul Paulman, Robert Taylor, Audrey

Paulman, Laeth Nasir, eds.

Cham, Switzerland: Springer International, 2016, 1,865 pp., \$599, hardcover

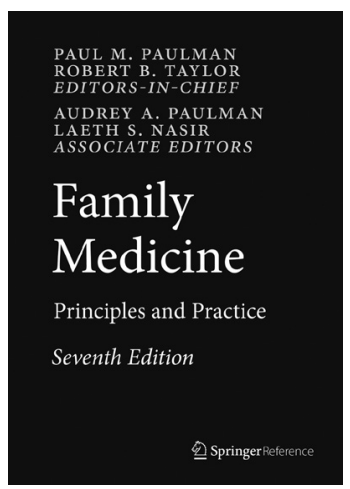

The editors-in-chief are well recognized in the field of family medicine, and well suited to editing a definitive textbook of this nature. Dr Paul Paulman is an active practitioner, teacher, administrator, and professor at the University of Nebraska Medical Cen-

ter, where he serves as professor of family medicine and assistant dean for clinical skills and quality. Dr Robert Taylor is well known in family medicine, with numerous scholarly contributions and textbooks to his name. He is a professor at Oregon Health and Science University, and has received the Award for Lifetime Contributions to Family Medicine by the American Academy of Family Physicians.

The authors and editors deserve a large amount of praise for the amount of material collected herein. Spanning nearly 2,000 pages, they have provided an up-to-date, readable update of the field. It is a most comprehensive field, and the editors have assembled a formidable array of information, in 133 chapters, to describe it. Each chapter is well organized and clearly written; brief enough to read at a sitting, yet detailed enough to justify inclusion in a textbook of this nature. Some material is sufficiently mature to be considered "classic", such as the expected chapters on diabetes and hypertension. Other chapters-such as on intimate partner violence, elder abuse, and autism spectrum disorders - provide fresh material to this ever-changing specialty.

Some of the material is clearly organized so as to be readily accessible to the practitioner, such as the material on care of acute lacerations, bites and stings. Others focus more on symptom-based presentations and differentials, such as care of the patient with fatigue. I personally enjoyed the historical perspective in the final chapter, on the evolution of family practice as a specialty.

The scholarly nature of this work and its comprehensiveness are beyond reproach. The 
fundamental question as to its value lies beyond the book itself, and in its format medium of print delivery. I am unable to answer the question of who is the audience for this work. This is an expensive, heavy, authoritative twovolume text. It can clearly not be used at the "bedside" (a term which itself may need updating). In a busy clinic, if one had to reach for a book, it may be more likely devoted to a specific topic, skill, or modality (such as excellent ones for minor emergencies, musculoskeletal procedures, dermatology photos, or ultrasound).

Now, all these topics appear as chapters in this one two-text volume, yet it seems akin to a pill containing an antihypertensive, a statin, and a hypoglycemic: great when you need all of them, unnecessary when you don't, and about impossible to update individual components.

For today's medical practice, this work and other references like it are beautifully crafted anachronisms, at least for contemporary US-based practice. That is not intended as an insult — placing the book in any residency clinical space (as I did) is an experiment all should be able to try. It remained untouched for a month; the current cohort of residents and faculty gravitating to Up To Date ${ }^{1}$ on smartphones for immediate answers; the above specific texts to look up visuals or skills (only if they had to, and if YouTube was down); standard family medicine journals for teaching purposes; and the occasional marked-up review book for those of us beholden to board recertification. I do not believe the e-book version would have fared any better; we are too entrenched in our routines to seek out new sources which our institutions may or may not have paid for.
The best way for this material to be adapted for use by the practicing family physician may be to embed it in places already used, in ways already (and newly) familiar, which will inevitably involve handheld devices at the point of care. Alternatively, it could still serve an important role in settings in the US and abroad where connectivity is minimal and reference books remain a staple of clinical education.

If there is a generational divide in US medical practice, clinical reference volumes are at the intersection-one rapidly receding in the distance. In the future, should there remain such a place as a medical library with books in it, this work surely belongs in it as one of the finest examples of family medicine references. For me, however, it is akin to the philosophical question of the (1,855 page) tree falling in the forest and no one being around to hear it. I am not sure what sound it makes.

doi: 10.22454/FamMed.2018.585487

\section{Omar Khan, MD, MHS}

Christiana Care Health System

Wilmington, DE

\section{References}

1. Wolters Kluwer. UpToDate. About Us. https://www.uptodate. com/home/about-us. Accessed June 20, 2016.

Reviewers interested in writing reviews for publication should contact Book and Media Reviews Editor William E. Cayley, Jr, MD, at bcayley@yahoo.com.

Publishers who wish to submit books for possible inclusion in Family Medicine's book reviews section should send texts to Society of Teachers of Family Medicine, 11400 Tomahawk Creek Parkway, Suite 240, Leawood, KS 66211. fmjournal@stfm.org

All books reviewed in this column are available for purchase at amazon.com through the STFM portal at www.stfm.org/bookstore. 